\title{
KAJIAN POTENSI DAN PENGELOLAAN BERKELANJUTAN EKOSISTEM MANGROVE PULAU PANNIKIANG, KABUPATEN BARRU, SULAWESI SELATAN
}

\section{STUDY OF POTENTIAL AND SUSTAINABLE MANAGEMENT OF MANGROVE ECOSYSTEM IN PANNIKIANG ISLAND, BARRU REGENCY, SOUTH SULAWESI}

\author{
Rismawaty Rusdi $^{*}$, Isdrajad Setyobudiandi ${ }^{2}$, \& Ario Damar ${ }^{2,3}$ \\ ${ }^{1}$ Program Studi Pengelolaan Sumberdaya Pesisir dan Lautan, FPIK, \\ Sekolah Pascasarjana IPB, Bogor, 16680, Indonesia \\ ${ }^{2}$ Departemen Manajemen Sumberdaya Perairan, FPIK-IPB, Bogor, 16680, Indonesia \\ ${ }^{3}$ Pusat Kajian Sumberdaya Pesisir dan Lautan, IPB, Bogor, 16680, Indonesia \\ *E-mail: rismawaty_rusdi@apps.ipb.ac.id
}

\begin{abstract}
The best planning and management can be fulfilled if complete and accurate information is available. This research generally aims to examine the potential of mangrove ecosystems on Pannikiang Island in terms of ecological conditions and economic value to assess sustainability status and determine mangrove ecosystem management recommendations. Ecological data collection was carried out by observation, interviews with purposive sampling method, and literature review. Ecological analysis used an important value index, economic analysis used consumer surplus, replacement cost, contingent value, and sustainability analysis used a modification of Rapid Appraisal for Fisheries (RAPFISH) software. The mangrove species that identified were Rhizophora apiculata, Rhizophora mucronata, Bruguiera gymnorrhiza, Bruguiera sexangula, Ceriops tagal, Sonneratia alba, Xylocarpus granatum, Xylocarpus moluccensis, Aegiceras corniculatum, Lumnitzera racemosa and Avicennia marina. The results analysis of the total economic value of mangrove ecosystem on Pannikiang Island with an area obout 86.31 ha was Rp5.050.275.373,00 /year or an average was Rp58.513.212,00 /ha/year. The sustainability status of the mangrove ecosystem on Pannikiang Island based on multidimensional analysis is still relatively unsustainable. Therefore, some strategy recommendations are rehabilitation of mangrove vegetation; controlling the utilization of mangrove ecosystems carried out by community, especially exploitative uses; involve community in mangrove ecosystems management; make formal regulation related to management of mangrove ecosystems.
\end{abstract}

Keywords: ecology, economy, mangrove ecosystem, sustainability

\begin{abstract}
ABSTRAK
Perencanaan dan pengelolaan yang baik hanya dapat dipenuhi apabila tersedia informasi yang lengkap dan akurat. Penelitian ini bertujuan untuk mengkaji potensi ekosistem mangrove di Pulau Pannikiang ditinjau dari kondisi ekologi dan nilai ekonomi untuk menilai status keberlanjutan dan menentukan rekomendasi pengelolaan ekosistem mangrove. Pengumpulan data ekologi, ekonomi, dan sosial dilakukan dengan metode observasi, wawancara dilakukan dengan metode purposive sampling, dan kajian literatur. Analisis ekologi menggunakan indeks nilai penting, analisis ekonomi menggunakan surplus consumer, replacement cost, contingent value, dan analisis keberlanjutan menggunakan modifikasi perangkat lunak Rapid Appraisal for Fisheries (RAPFISH). Jenis mangrove yang berhasil diidentifikasi adalah Rhizophora apiculata, Rhizophora mucronata, Bruguiera gymnorrhiza, Bruguiera sexangula, Ceriops tagal, Sonneratia alba, Xylocarpus granatum, Xylocarpus moluccensis, Aegiceras corniculatum, Lumnitzera racemosa and Avicennia marina. Hasil analisis nilai ekonomi total ekosistem mangrove di Pulau Pannikiang dengan luas 86,31 ha sebesar Rp5.050.275.373,00 /tahun atau rata-rata sebesar Rp58.513.212,00 /ha/tahun. Status keberlanjutan ekosistem mangrove di Pulau Pannikiang masih tergolong kurang berkelanjutan. Oleh karena itu, beberapa rekomendasi strategi yang disarankan adalah rehabilitasi vegetasi mangrove; mengendalikan kegiatan pemanfaatan
\end{abstract}


ekosistem mangrove yang bersifat eksploitatif; melibatkan masyarakat dalam kegiatan pengelolaan ekosistem mangrove; membuat peraturan secara formal terkait pengelolaan ekosistem mangrove.

Kata kunci: ekologi, ekonomi, ekosistem mangrove, keberlanjutan

\section{PENDAHULUAN}

Mangrove adalah salah satu ekosistem yang terletak di wilayah pesisir dan lautan yang berpotensi dalam menunjang kehidupan manusia dan keberlangsungan biota yang hidup di dalam dan di sekitarnya (Pattimahu et al., 2017). Potensi ekosistem mangrove mengandung arti kemampuan suatu ekosistem mangrove yang memiliki kemungkinan untuk dikembangkan. Potensi ekosistem mangrove dilihat dari aspek ekologi dan ekonomi, diantaranya sebagai penyedia jasa untuk sumberdaya perikanan, lokasi ekowisata, dan sumber mata pencaharian masyarakat lokal (Jusoff \& Dahlan, 2008; Kamal \& Haris, 2014; Mukherjee et al., 2014; Karlina et al., 2016; Winata et al., 2017).

Kabupaten Barru adalah kabupaten yang terletak di pesisir barat Provinsi Sulawesi Selatan dengan luas wilayah 1.175 $\mathrm{km}^{2}$ dan panjang garis pantai $78 \mathrm{~km}$. Berdasarkan Surat Keputusan Gubernur Sulawesi Selatan Nomor 2944 Tahun 2018, luas ekosistem mangrove di Pulau Pannikiang sebesar 86,31 ha dari total luas Pulau sebesar 94,50 ha dengan status pencadangan kawasan konservasi wilayah pesisir dan pulau-pulau kecil Kabupaten Barru.

Ekosistem mangrove memiliki nilai penting bagi masyarakat di Pulau Pannikiang karena sebagian besar pulau ditutupi oleh vegetasi mangrove, akan tetapi ekosistem ini juga rentan terhadap berbagai gangguan di sekitarnya. Meskipun Pulau Pannikiang memiliki ekosistem mangrove yang masih tergolong baik, pada beberapa lokasi telah mengalami degradasi akibat pemanfaatan lahan oleh masyarakat. Qamal (2019) menyatakan bahwa kerapatan mangrove di Pulau Pannikiang sejak 1998 hingga 2018 dengan kategori sangat padat berkurang sebesar 34,56 ha menjadi kategori sedang hingga sangat jarang. Beberapa kegiatan eksploitatif yang sering dilakukan oleh masyarakat pulau atau dari luar pulau adalah menebang pohon mangrove untuk dijadikan kayu bakar, bahan pembuatan alat tangkap tradisional, pembuatan rumah, dan membuka lahan di dalam ekosistem mangrove untuk memasang alat perangkap kelelawar. Berbagai masalah yang ada belum mampu ditangani oleh masyarakat karena keterbatasan kewenangan mereka dan belum adanya pengelolaan yang jelas oleh pemerintah setempat, meskipun kawasan ini telah dicadangkan sebagai kawasan konservasi.

Pengelolaan yang ada hanya sebatas pelarangan penebangan pohon mangrove, sementara pengelolaan yang baik adalah hasil dari proses perencanaan, pemantauan, dan evaluasi secara berkelanjutan. Pengelolaan yang baik hanya dapat dipenuhi apabila tersedia informasi yang lengkap dan akurat tentang kondisi ekosistem mangrove seperti kondisi vegetasi, potensi dan kegiatan sosial ekonomi serta aspek kelembagaan dan stakeholder yang berkepentingan terhadap pengelolaan kawasan mangrove. Oleh karena itu, penelitian secara umum bertujuan mengkaji potensi ekosistem mangrove di Pulau Pannikiang ditinjau dari kondisi ekologi dan nilai ekonomi total untuk menilai status keberlanjutan dan menentukan rekomendasi pengelolaan berdasarkan hasil analisis keberlanjutan.

\section{METODE PENELITIAN}

\subsection{Waktu dan Lokasi Penelitian}

Penelitian dilaksanakan pada bulan Oktober 2018-Januari 2019. Lokasi penelitian bertempat di Pulau Pannikiang, Kabupaten Barru, Sulawesi Selatan (Figure 1). 


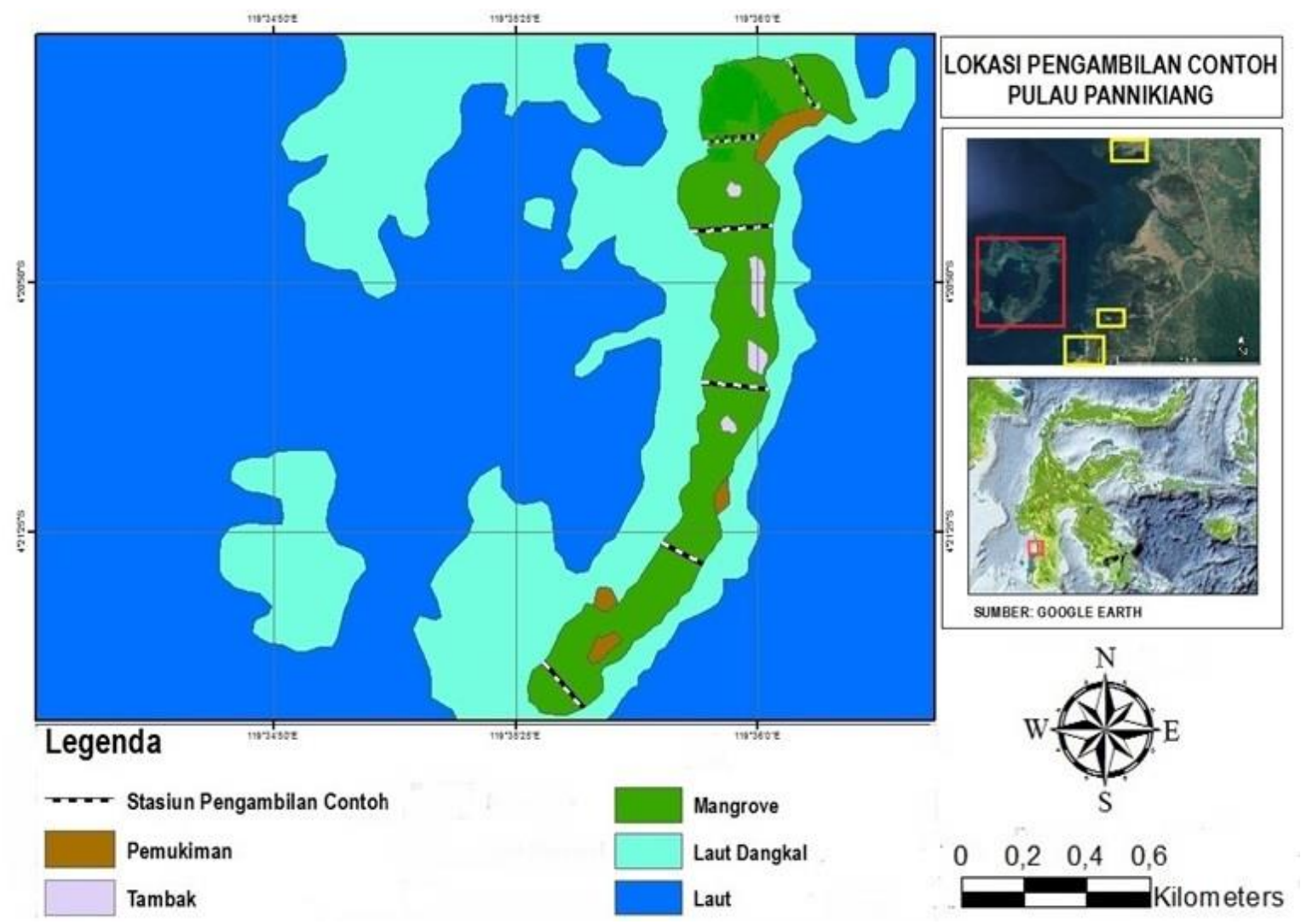

Figure 1. The research location at Pannikiang Island, Barru Regency, South Sulawesi.

\subsection{Jenis dan Sumber Data}

Data yang digunakan adalah data primer dan sekunder. Data primer didapatkan melalui pengamatan langsung di lapangan, sedangkan data sekunder dikumpulkan melalui Laporan Dinas Kelautan - Perikanan dan Universitas Muslim Indonesia tahun 2012.

\subsection{Prosedur Pengumpulan Data}

Data ekologi yang dikumpukan adalah kondisi vegetasi ekosistem mangrove. Metode yang digunakan adalah metode observasi dengan pengumpulan data menggunakan transek-kuadrat (MuellerDombois \& Ellenberg, 1974) dan spot check (Herison et al., 2014). Metode transekkuadrat (Figure 2) berukuran $10 \mathrm{~m} \times 10 \mathrm{~m}$ untuk kelompok pohon (diameter $>10 \mathrm{~cm}$ ). Kelompok pancang (diameter 2-10 cm) diambil pada petak berukuran $5 \mathrm{~m}$ x $5 \mathrm{~m}$. Kelompok semai (diameter $<2 \mathrm{~cm}$ ) diambil pada petak ukuran $1 \mathrm{~m} \mathrm{x} 1 \mathrm{~m}$.
Data ekonomi dan sosial meliputi jumlah dan struktur penduduk, mata pencaharian, tingkat pendidikan, dan kelembagaan yang diperoleh melalui wawancara dengan pengambilan contoh responden menggunakan metode purposive sampling dan penelusuran berbagai pustaka/ dokumen. Data tersebut digunakan dalam analisis nilai ekonomi dan analisis status keberlanjutan ekosistem mangrove. Jumlah responden yang mewakili masing-masing strata meliputi: masyarakat yang tinggal di Pulau Pannikiang (55 orang) dan wisatawan yang mengunjungi Pulau Pannikiang (34 orang).

Data yang digunakan untuk analisis penentuan status keberlanjutan dan leverage factor ditampilkan dengan multidimensional scalling serta dilakukan melalui wawancara mendalam terhadap responden (stakeholder) yang memenuhi persyaratan sesuai dengan keilmuan dan kewenangannya. Responden terdiri dari: Kepala Bidang Pemberdayaan 


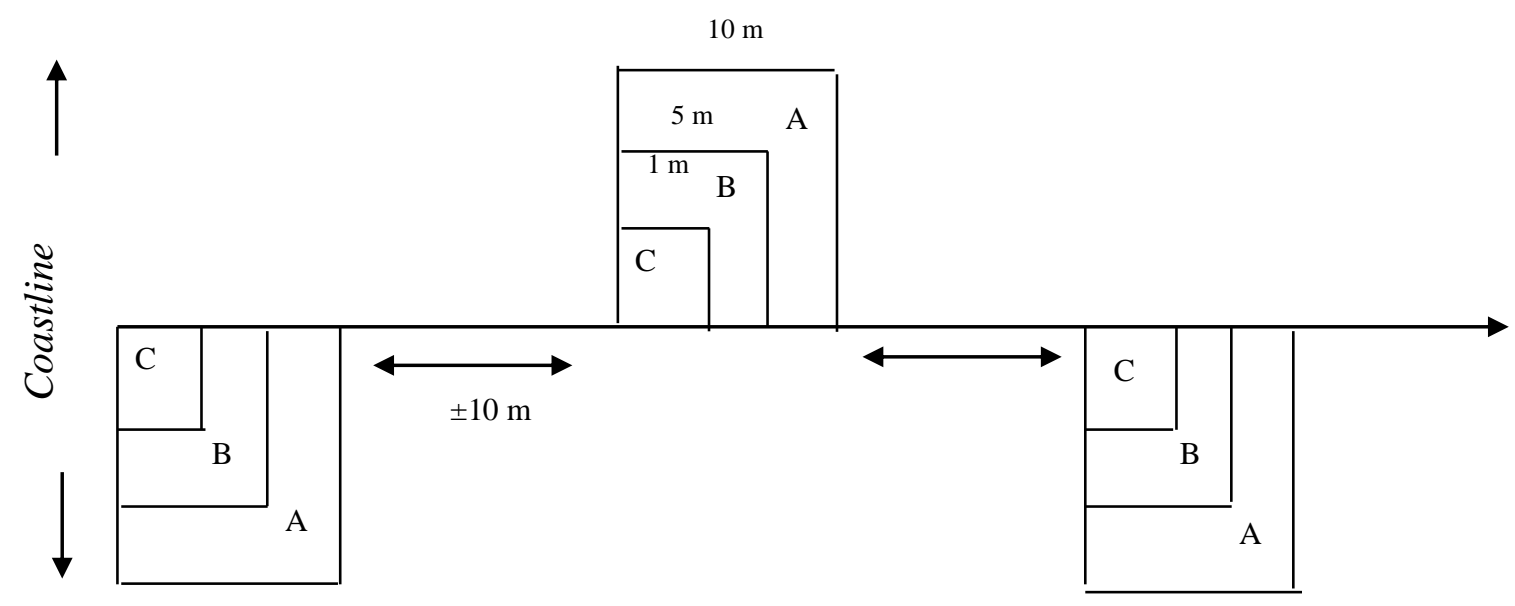

Figure 2. Placement of sample plots $(A=$ tree, $B=$ sapling, $C=$ seedling $)$.

Nelayan Kecil Dinas Perikanan Kabupaten Barru, Kepala Seksi Pengelolaan Pesisir dan Pulau-Pulau Kecil Dinas Perikanan Kabupaten Barru, Kepala Badan Perencanaan Pembangunan Daerah (BAPPEDA), Staf Bidang Destinasi Wisata Dinas Pariwisata (1 orang), Penyuluh Perikanan Pulau Pannikiang (1 orang), Kepala Desa dan staf desa Madello Kabupaten Barru (1 orang), tokoh masyarakat (1 orang), dan masyarakat (1 orang). Adapun data sekunder berupa data dan informasi yang berkaitan dengan keempat dimensi keberlanjutan diperoleh dari hasil penelitian dan literatur terkait.

\subsection{Analisis Data}

\subsubsection{Pengukuran Potensi Mangrove}

Data dasar dalam evaluasi struktur komunitas ekosistem mangrove adalah hasil perhitungan jumlah individu pada setiap satuan luas pengamatan dengan melakukan perhitungan nilai kerapatan jenis, kerapatan jenis relatif, penutupan jenis, penutupan jenis relatif, frekuensi jenis, dan frekuensi jenis relatif. Perhitungan ini dilakukan untuk mengetahui nilai penting struktur komunitas mangrove dan disajikan dalam rumus Indeks Nilai Penting (INP) (Curtis \& McIntosh, 1951; Mishra, 1968; Nugroho et al., 2019):

$\mathrm{INP}_{\mathrm{i}}=\mathrm{RD}_{\mathrm{i}}+\mathrm{RC}_{\mathrm{i}}+\mathrm{RF}_{\mathrm{i}}$
Keterangan: $\mathrm{INP}_{\mathrm{i}}=$ indeks nilai penting, jenis $\mathrm{i} ; \mathrm{RD}_{\mathrm{i}}=$ jumlah nilai kerapatan relatif jenis $\mathrm{i} ; \mathrm{RC}_{\mathrm{i}}=$ dominansi relatif jenis $\mathrm{i}$, dan $\mathrm{RF}_{\mathrm{i}}=$ frekuensi relatif jenis $i$.

\subsubsection{Nilai Ekonomi Total Ekosistem Mangrove}

Nilai-nilai yang diidentifikasi berdasarkan manfaat dan fungsi ekosistem mangrove di Pulau Pannikiang adalah nilai manfaat langsung, nilai manfaat tidak langsung, dan nilai keberadaan. Nilai manfaat langsung merupakan penilaian pemanfaatan sumberdaya ekosistem mangrove yang dihitung menggunakan metode market price (harga pasar), yaitu penjualan lokal untuk produk yang dipasarkan menggunakan harga bersih.

DUVK $_{i}=\left(H_{i} \times P_{i}\right)-B P_{i}$

Keterangan: DUVK $_{\mathrm{i}}=$ direct use value komoditas i (Rp), $\mathrm{HP}_{\mathrm{i}}=$ harga pasar komoditas i $(\mathrm{Rp} / \mathrm{kg}), \mathrm{P}_{\mathrm{i}}=$ produksi komoditas $\mathrm{i}(\mathrm{Kg} /$ tahun $), \mathrm{BP}_{\mathrm{i}}=$ biaya produksi komoditas i untuk semua nelayan (Rp), dan i $=$ jenis komoditas.

Nilai manfaat tidak langsung dari ekosistem mangrove dapat berupa manfaat fisik. Penilaian ekosistem mangrove secara fisik dapat diperkirakan dengan fungsi sebagai: (1) Penahan abrasi/pemecah 
gelombang yang diestimasi menggunakan metode replacement cost, yaitu biaya untuk memproduksi pemecah gelombang di sepanjang garis pantai yang dilindungi oleh ekosistem mangrove. Penilaian ini dirumuskan sebagai berikut:

$\mathrm{NPA}=\mathrm{B}_{\mathrm{pg}} \times \mathrm{M}_{\mathrm{pg}}$

Keterangan: NPA $=$ nilai pemecah gelombang $(\mathrm{Rp}), \mathrm{B}_{\mathrm{pg}}=$ biaya pembuatan pemecah gelombang $(\mathrm{Rp} / \mathrm{m})$, dan $\mathrm{M}_{\mathrm{pg}}=$ panjang garis pantai yang terlindung mangrove (m). (2) Kegiatan wisata yang diestimasi menggunakan biaya perjalanan wisata/travel cost method (TCM) berdasarkan nilai surplus konsumen yang meliputi biaya transport pulang pergi dan pengeluaran lain selama di perjalanan dan di dalam kawasan wisata (konsumsi, parkir, tiket masuk dan lain-lain) (Bergin \& Price, 1994; Fauzi, 2014; Limaei et al., 2014).

$$
\mathrm{CS}=\mathrm{U}-\mathrm{b}_{2}
$$

$\mathrm{DUVW}=\mathrm{CS} \mathrm{x} \mathrm{Q} / \mathrm{LK}$

Keterangan: $\mathrm{CS}=$ consumer surplus populasi, $\mathrm{b}_{2}=$ harga yang dibayarkan, $\mathrm{Q}=$ jumlah kunjungan populasi pertahun, $\mathrm{LK}=$ luas kawasan wisata mangrove (ha), dan DUVW $=$ direct use value wisata (Rp/ha/tahun).

Nilai manfaat keberadaan termasuk dalam nilai non-penggunaan yang dapat diperoleh berdasarkan kesediaan untuk membayar seseorang/willingness to pay (WTP) untuk keberadaan ekosistem mangrove (Zulkarnaini dan Mariana, 2016). Metode yang digunakan untuk menghitung nilai manfaat keberadaan yaitu contingent valuation method (CVM) (Fauzi, 2014). Nilai WTP diperoleh dengan rumus:

TWTP $=$ MWTP $\times \mathrm{N}$

Keterangan: TWTP $=$ total WTP responden
$(\mathrm{Rp}), \mathrm{MWTP}=\operatorname{rataan} \mathrm{WTP}(\mathrm{Rp}), \mathrm{N}=$ jumlah populasi (orang).

Perhitungan keseluruhan nilai ekonomi dilakukan menggunakan program Microsoft Excel 2010. Nilai ekonomi total merupakan penjumlahan nilai ekonomi keseluruhan dari manfaat ekosistem mangrove yang telah diidentifikasi dan dikuantifikasi. Nilai ekonomi total dirumuskan sebagai berikut:

$\mathrm{TEV}=\mathrm{DUV}+\mathrm{IUV}+\mathrm{EV}$

Keterangan: TEV = Total Economic Value $(\mathrm{Rp}), \mathrm{DUV}=$ Direct Use Value $(\mathrm{Rp}), \mathrm{IUV}=$ Indirect Use Value (Rp), dan $\mathrm{EV}=$ Exsistance Value (Rp).

\subsubsection{Status Keberlanjutan Pengelolaan Ekosistem Mangrove}

Analisis keberlanjutan ekosistem mangrove Pulau Pannikiang dilakukan dengan modifikasi perangkat lunak RAPFISH dengan pendekatan metode multidimensional scalling (MDS) (Pitcher \& Preikshot, 2001; Kavanagh \& Pitcher, 2004). Empat dimensi terkait dengan keberlanjutan ekosistem mangrove yang dinilai yaitu: ekologi, ekonomi, sosial, dan kelembagaan. Atribut yang digunakan untuk masingmasing dimensi sebanyak 5 atribut. Penentuan data atribut pada RAPFISH mengacu pada evaluasi RAPFISH oleh Pitcher et al. (2013) bahwa cakupan evaluasi RAPFISH setelah direvisi dari versi sebelumnya adalah memberi skor pada faktor ekologi dan ekosistem sebagai atribut yang akan mendorong atau menghambat kelestarian suatu sumberdaya.

Hasil status keberlanjutan menggambarkan keberlanjutan setiap dimensi yang dikaji dalam skala 0-100 (Pitcher \& Preikshot, 2001). Jika hasil analisis mempunyai nilai indeks $<50$ maka dapat dikatakan hasil dari dimensi tersebut belum atau tidak berkelanjutan, sebaliknya jika diperoleh nilai $>50$ berarti dapat dikatakan bahwa hasil dari dimensi tersebut 
berkelanjutan. Pada tahap selanjutnya dilakukan simulasi Monte Carlo dan analisis Leverage (Pitcher \& Preikshot, 2001).

\section{HASIL DAN PEMBAHASAN}

\subsection{Hasil}

\subsubsection{Kondisi Vegetasi Mangrove}

Berdasarkan hasil pengamatan dan identifikasi jenis mangrove diperoleh 6 famili yang terdiri dari 11 jenis (Table 1). Famili mangrove tersebut adalah Rhizophoraceae, Sonneratiaceae, Meliaceae, Myrsinaceae, Combretaceae, dan Avicenniaceae. Adapun jenis mangrove yang berhasil diidentifikasi adalah $R$. apiculata, $R$. mucronata, B. gymnorrhiza, B. sexangula, $C$. tagal, S. alba, X. granatum, X. moluccensis, A. corniculatum, L. racemosa dan A. marina. Kerapatan rata-rata kategori pohon, pancang, dan semai dan INP keseluruhan jenis mangrove yang ada dilokasi penelitian disajikan pada Table 2 dan Figure 3.

\subsubsection{Nilai Ekonomi Total Ekosistem Mangrove}

Berdasarkan hasil wawancara diketahui bahwa beberapa komoditas ikan yang berasosiasi dengan ekosistem mangrove dan sering ditangkap oleh nelayan adalah Ikan Lencam, Ikan Baronang Hitam, Ikan Belanak, dan Ikan Baronang Susu (Lai'Lai'). Hasil perhitungan dari keseluruhan ekosistem mangrove seluas 86,30 ha diperoleh total nilai manfaat langsung yang disajikan pada Table 3. Perhitungan total nilai manfaat tidak langsung yang diperoleh dari ekosistem mangrove Pulau Pannikiang dapat dilihat dari manfaat perlindungan pantai dan manfaat kegiatan ekowisata mangrove (Table 4). Perhitungan total nilai manfaat keberadaan yang diperoleh dari ekosistem mangrove Pulau Pannikiang dapat dilihat dari manfaat keberadaan oleh masyarakat dan wisatawan (Table 5). Nilai ekonomi total ekosistem mangrove di Pulau Pannikiang adalah penjumlahan dari nilai manfaat langsung, nilai manfaat tidak langsung, dan nilai manfaat keberadaan. Kuantifikasi manfaat keseluruhan disajikan pada Table 6.

\subsubsection{Status Keberlanjutan Ekosistem Mangrove}

Hasil dari analisis status keberlanjutan berupa nilai indeks untuk masing-masing dimensi dan atribut yang digunakan merupakan hasil kajian dari berbagai literatur yang nantinya akan mencerminkan status keberlanjutan dari dimensi tersebut. Hasil analisis keberlanjutan dan analisis monte carlo disajikan pada Table 7, hasil analisis keberlanjutan disajikan dalam diagram layang pada Figure 4, dan hasil analisis leverage disajikan berurutan pada Figure 5, 6, 7, dan 8.

Table 1. Distribution of mangrove species at each observation station.

\begin{tabular}{lllllllll}
\hline \multirow{2}{*}{ Family } & \multirow{2}{*}{ Mangrove types } & \multicolumn{1}{c}{ Local } & \multicolumn{5}{c}{ Distribution (Station) } \\
\cline { 3 - 8 } & & & I & II & III & IV & V & VI \\
\hline Rhizophoraceae & R. apiculata & Bakko & + & + & + & + & + & + \\
& R. mucronata & Bakko & - & - & + & + & + & + \\
& B. gymnorrhiza & Sala' - sala' & + & + & + & + & + & + \\
& B. sexangula & Sala' - sala' & + & + & + & + & + & + \\
Sonneratiaceae & C. tagal & Coke' - coke' & - & - & + & - & - & - \\
Meliaceae & X. granatum & Padada & + & + & + & + & + & + \\
& X. moluccensis & Tambu & + & - & - & - & - & - \\
Myrsinaceae & A. corniculatum & Utti - utti & - & - & - & + & + & + \\
Combretaceae & L. racemosa & Dulu' - dulu' & - & - & - & + & - & - \\
\hline
\end{tabular}




\begin{tabular}{cllllllll}
\hline \multirow{2}{*}{ Family } & \multirow{2}{*}{ Mangrove types } & \multirow{2}{*}{ Local } & \multicolumn{5}{c}{ Distribution (Station) } \\
\cline { 3 - 7 } & & I & II & III & IV & V & VI \\
\hline Avicenniaceae & A. marina & Api - api & - & - & - & - & - & + \\
\hline
\end{tabular}

Information: was found (+); not found (-); Source: Primary data, 2018.

Table 2. Average density of tree, sapling, and seedling categories for each station.

\begin{tabular}{lrrrrrr}
\hline \multirow{2}{*}{ Category } & \multicolumn{6}{c}{ Average density of each station (individu/ha) } \\
\cline { 2 - 7 } & \multicolumn{1}{c}{ I } & \multicolumn{1}{c}{ II } & III & \multicolumn{1}{c}{ IV } & \multicolumn{1}{c}{ V } \\
\hline Tree & 1.108 & 1.042 & 2.175 & 1.358 & 2.217 & 1.133 \\
Sapling & 667 & 600 & 1.667 & 933 & 1400 & 1.433 \\
Seedling & 41.667 & 19.167 & 17.500 & 16.667 & 31.667 & 25.000 \\
\hline
\end{tabular}

Table 3. Catches associated with the mangrove ecosystem on Pannikiang Island.

\begin{tabular}{clcc}
\hline No. & Description & $\begin{array}{c}\text { Economy Value } \\
(\text { Rp/year })\end{array}$ & Proportion (\%) \\
\hline 1 & Benefit of Belanakfish & 6.800 .000 & 22.63 \\
2 & Benefit of Baronang Hitam fish & 8.200 .000 & 27.29 \\
3 & Benefit of Baronang Susu fish & 5.900 .000 & 19.63 \\
4 & Benefit of Lencam fish & 9.150 .000 & 30.45 \\
\hline Total Value of Direct Benefits & 30.050 .000 & \\
\hline
\end{tabular}

Table 4. Total indirect use value of mangrove ecosystems at Pannikiang Island.

\begin{tabular}{ccc}
\hline No. & Description & $\begin{array}{c}\text { Economy Value } \\
\text { (Rp/year) }\end{array}$ \\
\hline 1 & Benefit of Coastal protection & 2.488 .994 .929 \\
2 & Benefit of Ecotourism & 2.511 .521 .415 \\
\hline Total Value of Indirect Benefits & 5.050 .938 .887 \\
\hline
\end{tabular}

Table 5. Total existence value of mangrove ecosystems at Pannikiang Island.

\begin{tabular}{lccc}
\hline Respondents & $\begin{array}{c}\text { WTP Average } \\
(\text { Rp/individu) }\end{array}$ & $\begin{array}{c}\text { Total Number } \\
\text { of Individual }\end{array}$ & $\begin{array}{c}\text { WTP Total } \\
\text { (Rp/year) }\end{array}$ \\
\hline Public & 143.237 & 90 & 12.891 .336 \\
Traveler & 27.270 & 250 & 6.817 .692 \\
\hline Total & & & 19.709 .029 \\
\hline
\end{tabular}

Table 6. Total economic value of mangrove ecosystems at Pannikiang Island.

\begin{tabular}{clcc}
\hline No. & Benefit Category & $\begin{array}{c}\text { Net Benefit Value } \\
\text { (Rp/year) }\end{array}$ & Proportion (\%) \\
\hline 1 & Direct benefit & 30.050 .000 & 0.39 \\
2 & Indirect benefit & 5.000 .516 .344 & 99.01 \\
3 & Benefits of existence & 19.709 .029 & 0.39 \\
\hline Total & & 5.050 .275 .373 & \\
\hline
\end{tabular}


Kajian Potensi dan Pengelolaan Berkelanjutan Ekosistem Mangrove ...

Table 7. RAPFISH analysis result of mangrove ecosystem management at Pannikiang Island.

\begin{tabular}{lcccccc}
\hline \multirow{2}{*}{ Dimension } & \multirow{2}{*}{ Stress } & \multirow{2}{*}{$R^{2}$} & \multicolumn{2}{c}{ Sustainability Index } & \multicolumn{2}{c}{ Monte Carlo Analysis } \\
\cline { 4 - 7 } & & & 2014 & 2018 & 2014 & 2018 \\
\hline Ecology & 0.18 & 0.93 & 61.58 & 57.01 & 57.51 & 53.95 \\
Economy & 0.15 & 0.95 & 20.79 & 16.68 & 13.94 & 9.55 \\
Social & 0.19 & 0.93 & 52.73 & 51.82 & 49.95 & 49.01 \\
Institutional & 0.19 & 0.93 & 45.84 & 46.40 & 41.78 & 41.23 \\
Multidimensional & 0.15 & 0.95 & 49.09 & 46.49 & 46.11 & 43.54 \\
\hline
\end{tabular}

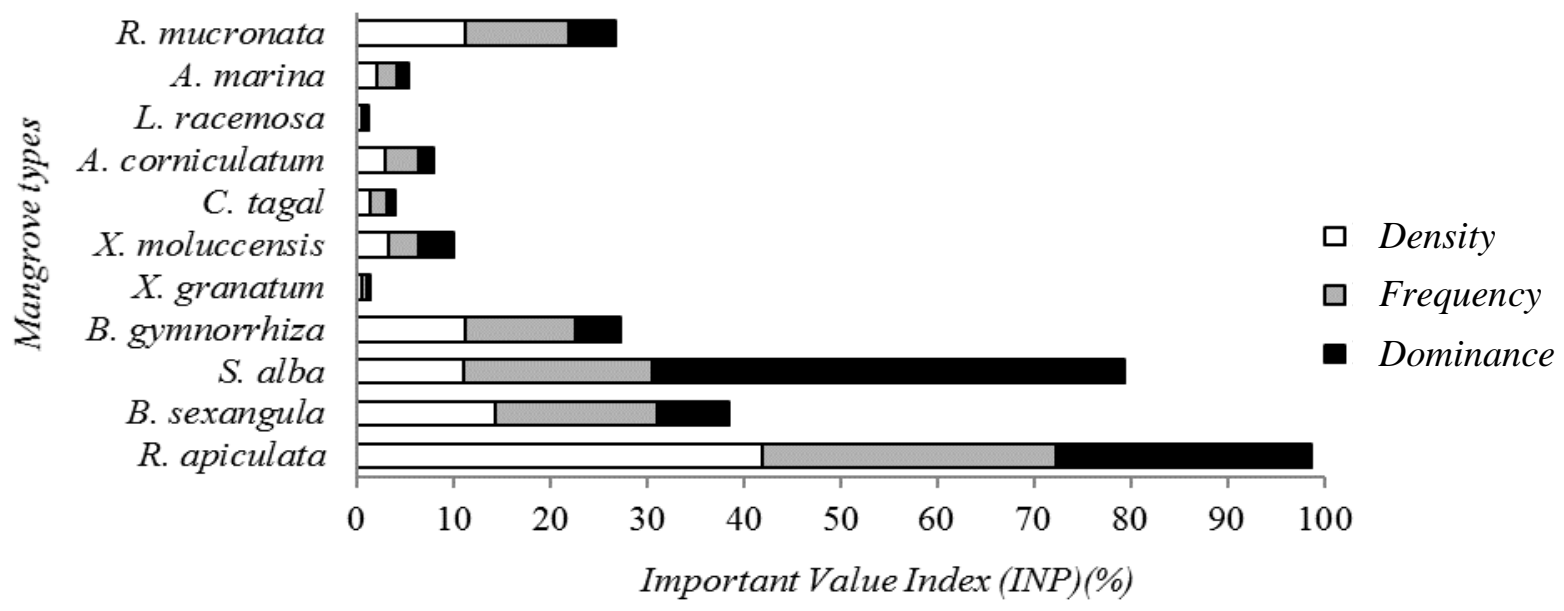

Figure 3. Important Value Index (INP) of mangrove species at Pannikiang Island.

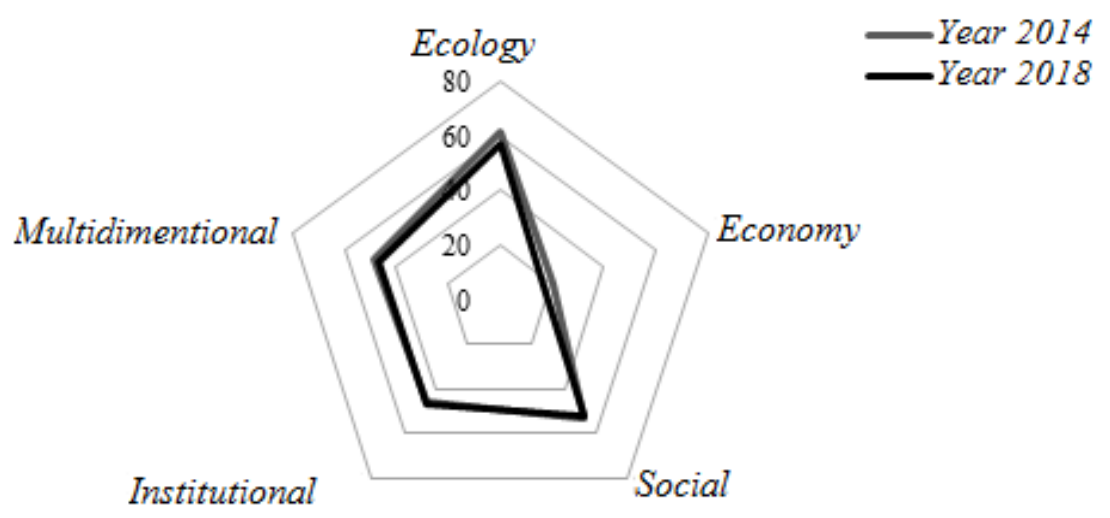

Figure 4. Kite diagram of mangrove ecosystem sustainability at Pannikiang Island.

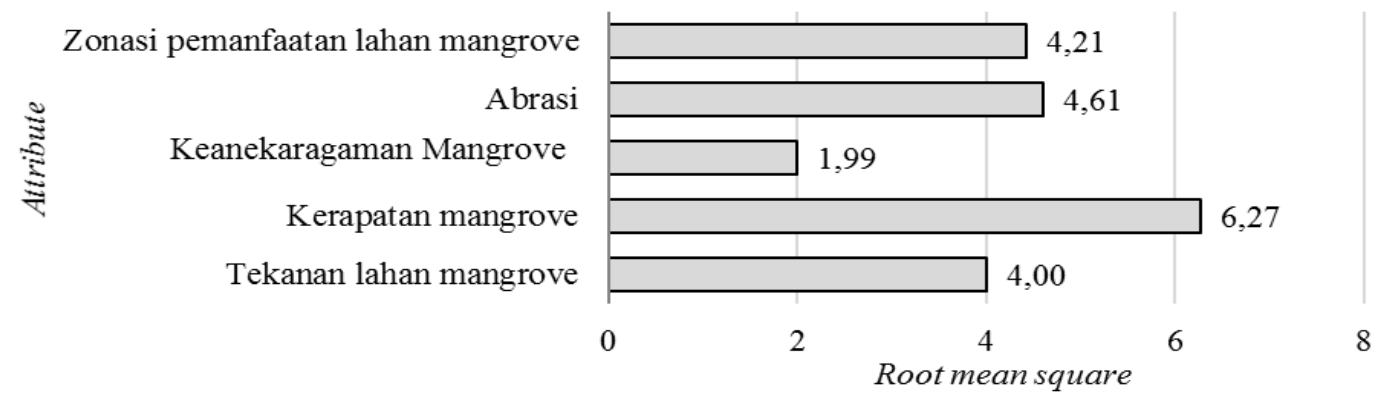

Figure 5. Leverage analysis of ecological dimension. 


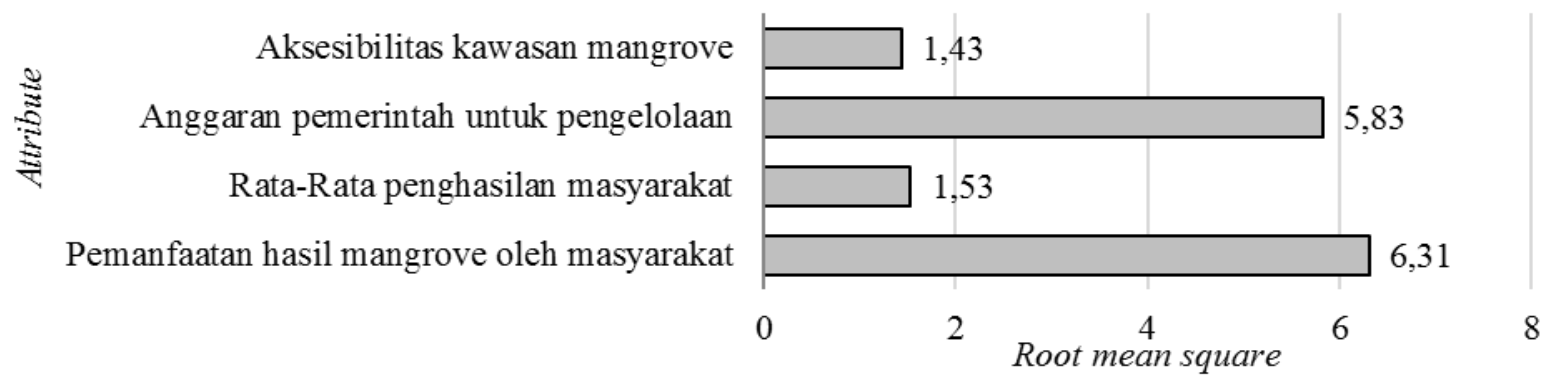

Figure 6. Leverage analysis of economic dimension.

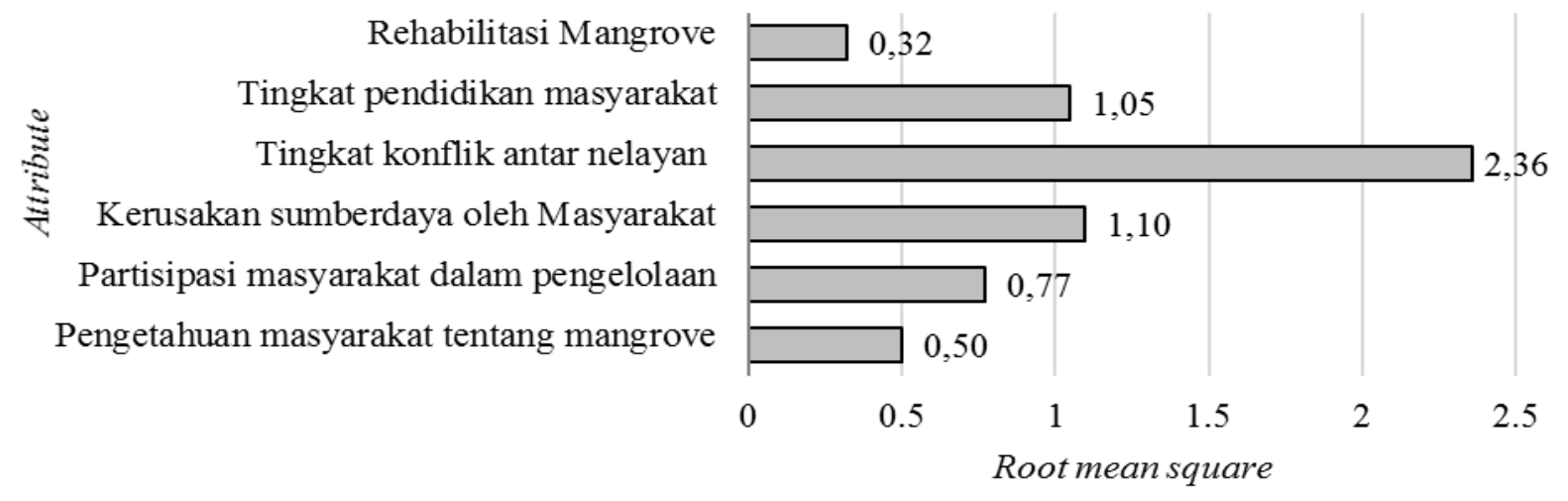

Figure 7. Leverage analysis of social dimension.

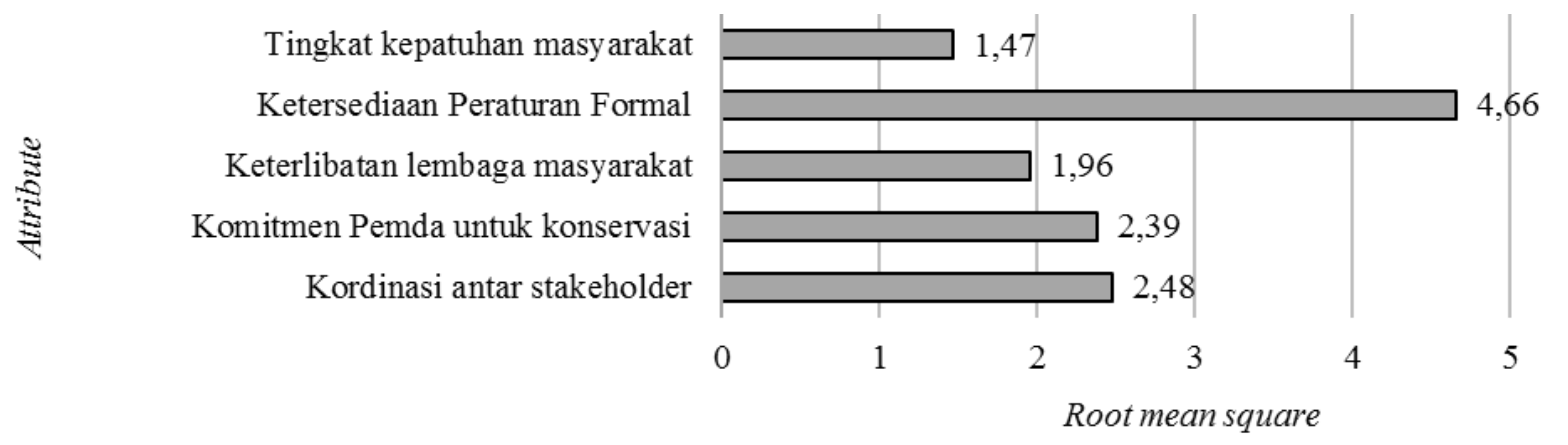

Figure 8. Leverage analysis of institutional dimension.

\subsection{Pembahasan}

\subsubsection{Kondisi Vegetasi Mangrove}

Potensi ekologi ekosistem mangrove di Pulau Pannikiang dapat dilihat dari distribusi jenis mangrove dan kerapatan jenis mangrove. Berdasarkan Table 1 dapat dilihat bahwa distribusi jenis mangrove menyebar di setiap stasiun pengamatan. Penyebaran setiap jenis mangrove dengan kerapatan yang tergolong padat dapat menjadi potensi objek wisata dan potensi alami untuk kelangsungan hidup biota yang ada di dalamnya.

Pada Table 2 menunjukkan bahwa kerapatan mangrove kategori pohon di Pulau Pannikiang dikategorikan sedang hingga sangat padat berdasarkan kriteria kerusakan mangrove yang dikeluarkan oleh Menteri Lingkungan Hidup dalam Keputusan Menteri Nomor 201 Tahun 2004. Kerapatan kategori pancang termasuk kategori jarang hingga padat, sedangkan kategori semai memiliki kerapatan yang padat. Regenerasi semai pada ekosistem mangrove merupakan salah satu bagian penting dalam proses suksesi sekunder (Mukhlisi \& Gunawan, 2016). Tingginya kerapatan semai pada semua stasiun pengamatan menandakan bahwa besarnya potensi yang dimiliki ekosistem mangrove di Pulau Pannikiang untuk beregenerasi secara alami. 
Berdasarkan Figure 3 diketahui bahwa 5 jenis yang mendominasi berdasarkan nilai INP adalah $R$. Apiculata sekitar 98,64\%, S. alba 79,35\%, B. sexangula $38,46 \%$, B. gymnorrhiza $27,28 \%$, dan $R$. mucronata 26,73\%. Sedangkan nilai INP terendah adalah $L$. racemosa sebesar $1,14 \%$ dan $X$. granatum sebesar $1,30 \%$. Kodikara et al., (2018) mengemukakan bahwa terdapat 6 jenis mangrove yang memiliki kemampuan adaptasi yang tinggi, 4 diantaranya adalah $R$. apiculata, B. sexangula, B. gymnorrhiza, dan R. mucronata.

\subsubsection{Nilai Ekonomi Total Ekosistem Mangrove}

Perhitungan terhadap nilai manfaat langsung ekosistem mangrove yang disajikan pada Table 3, yaitu menunjukkan bahwa proporsi terbesar dari nilai manfaat langsung adalah Ikan Lencam dan terendah adalah Ikan Baronang Susu. Lugendo et al., (2006); Honda et al., (2013) menyebutkan bahwa jenis ikan dari famili Lethrinidae sering ditemukan di ekosistem mangrove dan transisi antara lamun dan mangrove dan biasanya mencari makan di sela-sela akar mangrove, sedangkan ikan baronang saat juvenil biasanya mencari makan di sekitar ekosistem mangrove (Descasari et al., 2016; Muliati et al., 2017). Oleh karena itu, ikan Baronang susu yang ditemukan umumnya berukuran kecil dan harga jual di pasar juga rata-rata lebih rendah dibandingkan jenis lainnya.

Berdasarkan Table 4 terlihat bahwa manfaat tidak langsung terbesar diperoleh dari manfaat ekowisata dengan surplus konsumen sebesar Rp10.046.086,00 yang berarti bahwa wisatawan sebenarnya masih bersedia membayar lebih untuk melakukan kegiatan ekowisata mangrove di Pulau Pannikiang. Hal ini juga mendukung adanya potensi ekonomi untuk mengembangkan kegiatan wisata yang sudah ada.

Berdasarkan Table 5 diperoleh nilai manfaat keberadaan ekosistem mangrove sebesar Rp19.709.029,00 /tahun. Hasil wawancara dengan wisatawan dan masyarakat memperlihatkan bahwa tingkat pendidikan dan pendapatan yang tinggi cenderung akan memberikan nilai keberadaan yang tinggi dibandingkan dengan responden yang berpendidikan rendah atau pendapatannya rendah (Ezebilo, 2016; Pham et al., 2018).

Berdasarkan Table 6 diketahui bahwa nilai ekonomi total ekosistem mangrove di Pulau Pannikiang seluas 86,31 ha diperoleh sebesar Rp5.050.275.373,00 /tahun atau ratarata sebesar Rp58.513.212,00 /ha/tahun. Hasil ini menunjukkan bahwa ekosistem mangrove di Pulau Pannikiang memiliki peranan yang cukup besar bagi masyarakat baik yang dirasakan secara langsung ataupun tidak langsung. Jika dilihat dari nilai manfaat tidak langsung yang besar dapat dikatakan bahwa potensi ekosistem mangrove sebagai pengendali kualitas lingkungan khususnya sebagai penahan gelombang dan juga sebagai penyedia jasa kegiatan wisata sangat besar. Nilai manfaat ini tidak hanya dilihat dari ekonomi saja akan tetapi juga dari manfaat ekologi bagi kehidupan yang ada disekitarnya, baik itu biota yang berasosiasi ataupun masyarakat yang merasakan manfaatnya.

\subsubsection{Status Keberlanjutan Ekosistem Mangrove}

Berdasarkan Table 7 diketahui bahwa indeks keberlanjutan pada tahun 2014 lebih baik dibandingkan tahun 2018. Hal ini menunjukkan bahwa masa pembentukan pencadangan kawasan konservasi perairan di Pulau Pannikiang dari kabupaten ke provinsi khususnya pada ekosistem mangrove tidak memperlihatkan perubahan yang signifikan, akan tetapi jika dilihat dari nilai masingmasing dimensi pada tahun 2014 kondisi masih lebih baik jika dibandingkan tahun 2018 kecuali pada dimensi kelembagaan. Hal ini menunjukkan kelembagaan yang ada semakin membaik karena komitmen untuk melakukan kegiatan konservasi bersamasama sudah mulai terbentuk baik dari pihak 
masyarakat, perangkat desa, pemerintah kabupaten dan pemerintah provinsi.

Berdasarkan hasil analisis diperoleh nilai keberlanjutan ekosistem mangrove secara multidimensi dari Pulau Pannikiang pada tahun 2014 sebesar 49,09 dan pada tahun 2018 sebesar 46,49. Nilai tersebut menunjukkan bahwa masih tergolong kurang berkelanjutan. Hal ini disebabkan karena skor pada masing-masing atribut mengalami penurunan yang menandakan bahwa beberapa atribut dari seluruh dimensi yang dianalisis mengalami penurunan kualitas.

Diagram layang atau biasa disebut radar diagram menggambarkan status keberlanjutan secara terintegrasi antar dimensi, semakin dekat jarak hasil analisis dengan titik nol maka semakin menunjukkan rendahnya tingkat keberlanjutan. Berdasarkan Figure 4 diketahui bahwa dari empat dimensi yang dianalisis, dimensi ekonomi paling rendah tingkat keberlanjutannya. Hal ini menunjukkan bahwa perlu perhatian yang khusus untuk mengelola ekosistem mangrove dilihat dari sudut pandang ekonomi untuk meningkatkan status keberlanjutan ekosistem mangrove di Pulau Pannikiang. Selain aspek ekonomi yang perlu diperhatikan juga adalah aspek kelembagaan yang masih tergolong kurang berkelanjutan. Pengelolaan suatu ekosistem tidak bisa hanya dari satu aspek, harus ada integrasi antar aspek agar pengelolaan yang ada lebih terpadu dan berkelanjutan.

Pengelolaan secara terpadu dan berkelanjutan dapat dikaji dengan menggabungkan atribut sensitif dari hasil analisis leverage dari seluruh dimensi. Berdasarkan Figure 5, kerapatan mangrove adalah atribut yang paling sensitif. Pengaruh kerapatan ini sangat besar bagi keberlanjutan suatu ekosistem mangrove. Oleh karena itu, hal utama yang harus dikelola agar ekosistem mangrove tetap berkelanjutan adalah menjaga kerapatan ekosistem mangrove dari berbagai ancaman dan tekanan. Menurut Carugati et al., (2018); Kawaroe et al.,
(2001), ekosistem mangrove adalah salah satu ekosistem pesisir paling produktif di bumi yang jika mengalami kerusakan akan menurunkan fungsinya sebagai ekosistem pelindung.

Berdasarkan Figure 6, pemanfaatan hasil mangrove adalah atribut yang paling sensitif. Pemanfaatan ekosistem mangrove oleh masyarakat masih bersifat eksploitatif. Pemanfaatan dilakukan tidak hanya oleh masyarakat pulau tetapi juga dari luar pulau. Dengan kondisi ekosistem mangrove yang masih tergolong cukup baik dan belum ada pengelolaan tentu membuat peluang yang besar untuk dimanfaatkan secara terus menerus, sehingga akan menyebabkan kerusakan dalam jangka panjang.

Berdasarkan Figure 7, konflik antar nelayan merupakan atribut yang paling sensitif. Konflik antar nelayan dalam hal ini adalah wilayah penangkapan. Berdasarkan hasil wawancara, masyarakat tradisional mengalami penurunan pendapatan karena nelayan dari luar menggunakan alat dan sarana yang lebih modern dan tidak ramah lingkungan. Masyarakat yang menangkap di sekitar ekosistem mangrove mengandalkan hasil tangkapan berupa ikan yang berasosiasi dengan ekosistem mangrove dengan alat pancing, akan tetapi beberapa nelayan modern dari luar pulau justru datang menangkap ikan dengan alat yang tidak ramah lingkungan seperti bom ikan dan jaring.

Berdasarkan Figure 8, ketersediaan peraturan formal adalah atribut yang paling sensitif. Ketersediaan peraturan formal sangat penting agar seluruh stakeholder dan masyarakat memiliki pedoman yang kuat dalam mengelola ekosistem mangrove. Fungsi peraturan formal ini adalah sebagai kebijakan (rencana) yang ingin dicapai untuk menjawab berbagai kepentingan masyarakat. Adanya peraturan secara formal menjadikan masyarakat lebih berani untuk bertindak dalam menjaga kelestarian sumberdayanya. 
Table 8. Recommended strategies for improving sustainability status of Pannikiang Island mangrove ecosystem.

\begin{tabular}{|c|c|}
\hline Dimension & Strategy \\
\hline Ecology & $\begin{array}{l}\text { Rehabilitasi vegetasi mangrove. Kegiatan rehabilitasi disarankan pada } \\
\text { stasiun II, III, dan IV dimana terdapat beberapa lahan yang dibuka dan } \\
\text { sudah tidak berfungsi untuk tambak. Kegiatan rehabilitasi sebaiknya } \\
\text { dilakukan setiap tahun agar kondisi mangrove tetap terjaga kelestariannya. }\end{array}$ \\
\hline Economy & $\begin{array}{l}\text { Mengendalikan kegiatan pemanfaatan ekosistem mangrove yang dilakukan } \\
\text { oleh masyarakat khususnya pemanfaatan yang bersifat eksploitatif. Lokasi } \\
\text { pemanfaatan disarankan pada stasiun I dikarenakan kondisi kerapatan semai } \\
\text { yang lebih baik dibadingkan stasiun lainnya. Kegiatan pemanfaatan tidak } \\
\text { boleh bersifat eksploitatif dan harus mempertimbangkan jenis mangrove di } \\
\text { setiap stasiun dan akses yang mudah untuk direhabilitasi kembali. }\end{array}$ \\
\hline Social & $\begin{array}{l}\text { Melibatkan masyarakat dalam kegiatan pengelolaan ekosistem mangrove. } \\
\text { Keterlibatan masyarakat dalam pengelolaan harus dilakukan secara } \\
\text { menyeluruh mulai dari tahap perencanaan hingga monitoring dan evaluasi. } \\
\text { Masyarakat yang terlibat juga harus dari dua lokasi pemukiman agar tidak } \\
\text { terjadi konflik. }\end{array}$ \\
\hline Institutional & $\begin{array}{l}\text { Membuat peraturan formal yang terintegrasi terkait pengelolaan ekosistem } \\
\text { mangrove. Peraturan formal yaitu Peraturan Menteri Koordinator Bidang } \\
\text { Perekonomian Nomor } 4 \text { Tahun } 2017 \text { tentang kebijakan, strategi, program, } \\
\text { dan indikator kinerja pengelolaan ekosistem mangrove nasional dijabarkan } \\
\text { bahwa tujuan dari nilai penting peraturan perundang-undangan adalah } \\
\text { mewujudkan kebijakan terpadu dalam pengelolaan ekosistem mangrove di } \\
\text { Indonesia sehingga dibutuhkan penyusunan strategi pengelolaan ekosistem } \\
\text { mangrove di tingkat provinsi dan daerah dengan mengadopsi dan } \\
\text { mengintegrasikan strategi pengelolaan ekosistem mangrove ke dalam } \\
\text { dokumen rencana pembangunan dan rencana tata ruang dan atau rencana } \\
\text { zonasi wilayah pesisir dan pulau-pulau kecil. Hal ini kemudian belum } \\
\text { dilaksanakan oleh pihak/instansi terkait pengelolaan ekosistem mangrove } \\
\text { sehingga perlu menjadi perhatian. }\end{array}$ \\
\hline
\end{tabular}

\subsubsection{Rekomendasi Pengelolaan Ekosistem Mangrove}

Hasil atribut prioritas dari analisis leverage menunjukkan bahwa beberapa atribut memiliki nilai yang paling tinggi pengaruhnya terhadap skor keberlanjutan ekosistem mangrove. Hasil dari prioritas pengelolaan berdasarkan analisis keberlanjutan ekosistem mangrove di Pulau Pannikiang, kemudian dikembangkan untuk menyusun beberapa rekomendasi strategi yang disajikan pada Table 8.

\section{KESIMPULAN}

Potensi ekosistem mangrove di Pulau Pannikiang baik secara ekologi maupun ekonomi perlu dikembangkan sesuai dengan tujuan untuk dijadikan kawasan konservasi. Status keberlanjutan ekosistem mangrove di Pulau Pannikiang berdasarkan hasil analisis multidimensi masih tergolong kurang berkelanjutan sehingga beberapa rekomendasi dari dimensi ekologi, ekonomi, sosial, dan kelembagaan diperlukan untuk meningkatkan status keberlanjutan. 


\section{UCAPAN TERIMA KASIH}

Ucapan terima kasih kepada pemerintah daerah Kabupaten Barru dan Penyuluh Perikanan Kabupaten Barru atas diskusi, saran, dan bantuannya selama kegiatan penelitian.

\section{DAFTAR PUSTAKA}

Bergin, J. \& C. Price. 1994. The travel cost method and landscape quality. Landscape Research, 19(1): 21-23. https://doi.org/10.1080/01426399408 706416

Carugati, L., B. Gatto, E. Rastelli, M.L. Martire, C. Coral, S. Greco, \& R. Danovaro. 2018. Impact of mangrove forests degradation on biodiversity and ecosystem functioning. Scientific Reports, 8(13298): 1-11. https://doi.org/10.1038/s41598-01831683-0

Curtis, J.T. \& R.P. McIntosh. 1951. An upland forest continuum in the prairie-forest border region of Wisconsin. Ecology, 32(3): 476-496. http://www.jstor.org/stable/1931725

Descasari, R., I. Setyobudiandi, \& R. Affandi. 2016. Keterkaitan ekosistem mangrove dengan keanekaragaman ikan di Pabean Ilir dan Pagirikan, Kabupaten Indramayu, Jawa Barat. Bonorowo Wetlands, 6(1): 43-58. https://doi.org/10.13057/bonorowo/w 060104

Dinas Perikanan Kelautan Provinsi Sulawesi Selatan dan Universitas Muslim Indonesia. 2012. Laporan Akhir Identifikasi dan Pemetaan Potensi Sumberdaya Pulau Pannikiang Kabupaten Barru. Makassar. Dinas Kelautan Perikanan. Provinsi Sulawesi Selatan. 105 p.

Ezebilo, E. 2016. Willingness to pay for maintenance of a nature conservation area: a case of mount Wilhelm, Papua
New Guinea. Asian Social Science, 12(9): 149-161.

https://doi.org/10.5539/ass.v12n9p14 9

Fauzi, A. 2014. Valuasi ekonomi dan penilaian kerusakan sumber daya alam dan lingkungan. IPB Press. Bogor. 245 p.

Herison, H., F. Yulianda, C. Kusmana, I.W. Nurjaya, \& L. Adrianto. 2014. The existing condition of mangrove region of Avicennia marina: Its distribution and functional transformation. $J$. of Tropical Forest Management, 20(1): 26-34.

https://doi.org/10.7226/jtfm.20.1.26

Honda, K., Y. Nakamura, M. Nakaoka, W.H. Uy, \& M.D. Fortes. 2013. Habitat use by fishes in coral reefs, seagrass beds, and mangrove habitats in the Philippines. PloS ONE, 8(8): 1-10. https://doi.org/10.1371/journal.pone.0 065735

Jusoff, K. \& D.H. Dahlan. 2008. Managing sustainable mangrove forests in Peninsular Malaysia. J. of Sustainable Development, 1(1): 88-96. https://doi.org/10.5539/jsd.v1n1p88

Kamal, E. \& H. Haris. 2014. Komposisi dan vegetasi hutan mangrove di pulaupulau kecil, di Pasaman Barat. Ilmu Kelautan, 19(2):113-120. https://doi.org/10.14710/ik.ijms.19.2. 113-120

Karlina, E., C. Kusmana, Marimin, \& M. Bismark . 2016. Analisis keberlanjutan pengelolaan hutan lindung mangrove di Batu Ampar, Kabupaten Kubu Raya, Provinsi Kalimantan Barat. J. Analisis Kebijakan, 13(3): 201-219. https://doi.org/10.20886/jakk.2016.13 .3.201-219

Kavanagh, P. \& T.J. Pitcher. 2004. Rapid appraisal of fisheries (RAPFISH) project. University of British Columbia, Fisheries Centre, 
Vancouver. Fisheries Centre

Research, 2(12): 1-75.

http://www.fao.org/tempref/docrep/fa

o/005/x4175e/X4175E00.pdf

Kawaroe, M., D.G. Bengen, M. Eidman, \&

M. Boer. 2001. Kontribusi ekosistem mangrove terhadap struktur komunitas ikan di pantai utara Kabupaten Subang, Jawa Barat. J. Pesisir dan Lautan, 3(3): 12-25.

Kodikara, K.A.S., L.P. Jayatissa, M. Huxham , F. Guebas, \& N. Koedam. 2017. The effects of salinity on growth and survival of mangrove seedlings changes with age. Acta Botanica Brasilica, 32(1): 37-46.

https://doi.org/10.1590/0102$33062017 \mathrm{abb} 0100$

Limaei, S.M., H. Ghesmati, R. Rashidi, \& N. Yamini. 2014. Economic evaluation of natural forest park using the travel cost method (case study; Masouleh forest park, north of Iran. J. of Forest Science, 60(6): 254-261.

https://www.agriculturejournals.cz/pu blicFiles/125766.pdf

Lugendo, B.R., I. Nagelkerken, V.D. Velde, \& Y.D. Mgaya. 2006. The importance of mangroves, mud and sand flats, and seagrass beds as feeding areas for juvenile fishes in Chwaka Bay, Zanzibar: gut content and stable isotope analysis. J. of Fish Biology, 69: 1639-1661.

https://doi.org/10.1111/j.1095-

8649.2006.01231.x

Mishra, R. 1968. Ecology Workbook. Oxford and IBH Publishing Company. Calcutta. 242 p.

Mueller-Dombois, D. \& H. Ellenberg. 1974. The Count-Plot Method and Plotless Sampling Techniques. Wiley \& Sons. New York. 135 p.

Mukherjee, N, W.J. Sutherland, L. Dicks, J. Huge, N. Koedam, \& G.F. Dahdouh. Ecosystem service valuations of mangrove ecosystem to inform decision making and future valuation exercises. PloS ONE, 9(9): 1-9. https://doi.org/10.1371/journal.pone.0 107706

Mukhlisi \& W. Gunawan. 2016. Regenerasi alami semai mangrove di areal terdegradasi Taman Nasional Kutai. J. Penelitian Kehutanan Wallacea, 5(2): 113-122.

http://doi.org/10.18330/jwallacea.201 6.vol5iss2pp113-122

Muliati, F., Yasidi, \& H. Arami. 2017. Studi kebiasaan makanan ikan baronang (Siganus canaliculatus) di perairan Tondonggeu, Kecamatan Abeli, Sulawesi Tenggara. J. Manajemen Sumber Daya Perairan, 2(4): 287294.

Nugroho, T.S., A. Fahrudin, F. Yulianda, \& D.G. Bengen. 2019. Structure and composition of riverine and fringe mangroves at Muara Kubu protected areas, West Kalimantan, Indonesia. AACL Bioflux, 12 (1): 378-393.

http://www.bioflux.com.ro/docs/2019 .378-393.pdf

Pattimahu, D.V., A. Kastanya, \& P.E. Papilaya. 2017. Sustainable mangrove forest management analysis (a case study from Dusun Taman Jaya, West Seram Regency, Maluku). International J. of Applied Engineering Research, 12(24): 14895-14900.

Pham, T.D., N. Kaida, K. Yoshino, X.H. Nguyen, H.T. Nguyen, \& D.T. Bui. 2018. Willingness to pay for mangrove restoration in the context of climate change in the $\mathrm{Cat} \mathrm{Ba}$ biosphere reserve, Vietnam. Ocean and Coastal Management. 163(2018): 269-277.

https://doi.org/10.1016/j.oceacoaman. 2018.07.005

Pitcher, T.J. \& D. Preikshot. 2001. RAPFISH: a rapid appraisal technique to evaluate the 
sustainability status of fisheries. Fisheries Research, 49: 255-270. https://doi.org/10.1016/S01657836(00)00205-8

Qamal, A.I.R. 2019. Perubahan luas dan kerapatan hutan mangrove Pulau Pannikiang, Kabupaten Barru. $J$. Environmental Science, 1(2): 1-7. https://ojs.unm.ac.id/JES/article/view/ 9054

Winata, A., E. Yuliana, \& E. Rusdiyanto. 2017. Diversity and natural regeneration of mangrove in the tracking area on Kemujan Island,
Karimunjawa National Park, Indonesia. AES Bioflux, 9(2): 109119.

http://www.aes.bioflux.com.ro/docs/2 017.109-119.pdf

Zulkarnaini \& Mariana. 2016. Economic valuation of mangrove forest ecosystem in Indragiri estuary. International $J$. of Oceans and Oceanography, 10(1): 13-17.

Received : :20 May 2019

Reviewed : 30 October 2019

Accepted : 24 March 2020 
